\title{
Relative Bioavailability of Chewable and Conventional Film-Coated Tablet Formulations of Sildenafil 100 mg in Healthy Volunteers Under Fasting Conditions
}

Fermin Valenzuela ${ }^{1 *}$, Gabriela Davila², Yamanqui Ibañez ${ }^{1}$, Luis Garcia ${ }^{1}$, Penelope Crownover ${ }^{3}$, Regina Gómez-Palacio², Juan Ovalle², Cesar Velasco ${ }^{2}$ and Bimal Malhotra ${ }^{3}$

${ }^{1}$ Investigación Farmacológica y Biofarmacéutica, S.A. de C.V., México D.F., Mexico

${ }^{2}$ Pfizer Mexico, México D.F., Mexico

${ }^{3}$ Pfizer Inc, New York, NY, USA

\begin{abstract}
Pharmacokinetics and bioavailability of a chewable tablet formulation of sildenafil citrate $100 \mathrm{mg}$ developed using taste-masking technology and taken with or without water (chewed until full disintegration and then swallowed) versus the conventional film-coated sildenafil tablet $\left(\right.$ Viagra $\left.^{\circledR}\right)$ taken with water were evaluated in the fasted state in a randomized, open-label, single-dose, 3-period crossover study in 30 healthy men aged 18 to 40 years (mean \pm SD, $24 \pm 4$ y). Sildenafil plasma concentrations were determined using a validated high-performance liquid chromatography method with ultraviolet detection. Bioequivalence criteria were $90 \%$ classic and Westlake Cls within $80 \%$ to $125 \%$ for test/reference ratios; limit tests applied were Schuirmann unilateral double $t$ test and the Anderson-Hauck test. For area under the curve (AUC), bioequivalence criteria were met for all the treatments studied. For maximum plasma concentration $\left(\mathrm{C}_{\mathrm{mx}}\right)$, bioequivalence criteria were met for the chewable tablet with water relative to Viagra when using the Westlake $\mathrm{Cl}$. The chewable tablet without water had equivalent AUC, but the $\mathrm{C}_{\max }$ was up to $22 \%$ lower when compared with Viagra or with the chewable tablet with water. Median time to $C_{\text {max }}$ was lowest for the chewable tablet with water $(0.75 \mathrm{~h})$ versus Viagra $(1.0 \mathrm{~h})$ or the chewable tablet without water $(1.75 \mathrm{~h})$. Adverse events with the chewable tablet were consistent with the tolerability profile of Viagra. Only 1 ( $3 \%$, chewable tablet with water) and $4(13 \%$, chewable tablet without water) subjects reported bitter taste, demonstrating successful taste masking.
\end{abstract}

Keywords: Bioavailability; Bioequivalence; Chewable; Dosage forms; Pharmacokinetics; Sildenafil

Abbreviations: $\mathrm{AUC}_{0 \text {-inf }}$ : Area under the plasma concentration versus time curve from time 0 extrapolated to infinity; $\mathrm{AUC}_{0-\mathrm{t}}$ : Area under the plasma concentration versus time curve from time 0 to time $\mathrm{t} ; \mathrm{C}_{\text {maximum }}$ : Masma concentration; $\mathrm{K}$ : Elimination rate constant; $\mathrm{t}_{1 / 2}$ : Elimination half-life; $\mathrm{T}_{\max }$ : Time to reach $\mathrm{C}_{\max }$

\section{Introduction}

Sildenafil citrate is a phosphodiesterase type 5 inhibitor. In countries worldwide, including Mexico, sildenafil citrate is approved for the treatment of erectile dysfunction as conventional film-coated tablets of 50-mg and 100-mg strengths for oral administration with water (Viagra', Pfizer Inc, New York, NY). Viagra is rapidly absorbed, reaching a mean maximum plasma concentration $\left(\mathrm{C}_{\text {max }}\right)$ of $514 \mathrm{ng} / \mathrm{mL}$ within 30 to 120 minutes (median, $60 \mathrm{~min}$ ) after oral administration of the 100-mg dose in the fasted state [1]. Mean terminal half-life $\left(t_{1 / 2}\right)$ is approximately 4 hours [1]. The absolute average bioavailability after oral administration is about $41 \%[1,2]$. For doubling the dose, across the range of 25-200 mg, a small and clinically insignificant degree of non-proportionality was observed in predicted increases in $\mathrm{C}_{\text {max }}(2.1$ fold) and in area under the plasma concentration versus time curve (AUC, 2.2-fold) [1].

A chewable tablet formulation of sildenafil citrate has been developed that does not have to be swallowed whole. Because citrate salts have a bitter taste, taste masking was essential to improve the palatability of the chewable tablet formulation.

The primary aim of this study was to evaluate the pharmacokinetics and bioavailability of sildenafil from its chewable tablet formulation taken with or without water relative to the marketed conventional filmcoated tablet taken with water. Secondary objectives were to assess the tolerability and palatability of the new formulation.

\section{Materials and Methods}

\section{Study design}

This was a randomized, open-label, 3-period, 6-sequence, crossover trial in 30 healthy male volunteers aged 18 to 40 years, with body mass indices between 18 and $27 \mathrm{~kg} / \mathrm{m}^{2}$. Subjects were given single oral doses of the following 3 treatments after an overnight fast: Viagra 100-mg tablet with $250 \mathrm{~mL}$ of water; sildenafil citrate $100-\mathrm{mg}$ chewable tablet with $250 \mathrm{~mL}$ of water, and sildenafil citrate $100-\mathrm{mg}$ chewable tablet without water. Treatments were separated by 1 -week washout periods between consecutive doses. Subjects were instructed to chew the chewable tablet until full disintegration and then swallow it, with or without water, depending on the treatment. Each subject was randomized to receive the 3 treatments in 1 of 6 possible sequences.

Health status was assessed based on physical examinations, medical records, electrocardiograms, and clinical laboratory results at

*Corresponding author: Fermin Valenzuela, Investigación Farmacológica y Biofarmacéutica, S.A. de C.V., Av. Periférico Sur 4927, Arenal Tepepan, Tlalpan, México D.F., CP 14610, Mexico, Tel: +52-55-24583115; Fax: +52-55-24583118 E-mail: fvalenzuela@ifab.com.mx,fvgg@prodigy.net.mx

Received August 17, 2011; Accepted October 22, 2011; Published October 24 2011

Citation: Valenzuela F, Davila G, Ibañez Y, Garcia L, Crownover P, et al. (2011) Relative Bioavailability of Chewable and Conventional Film-Coated Table Formulations of Sildenafil $100 \mathrm{mg}$ in Healthy Volunteers Under Fasting Conditions. J Bioequiv Availab 3: 207-210. doi:10.4172/jbb.1000087

Copyright: (C) 2011 Valenzuela F, et al. This is an open-access article distributed under the terms of the Creative Commons Attribution License, which permits unrestricted use, distribution, and reproduction in any medium, provided the original author and source are credited. 
Citation: Valenzuela F, Davila G, Ibañez Y, Garcia L, Crownover P, et al. (2011) Relative Bioavailability of Chewable and Conventional Film-Coated Tablet Formulations of Sildenafil $100 \mathrm{mg}$ in Healthy Volunteers Under Fasting Conditions. J Bioequiv Availab 3: 207-210. doi:10.4172/ jbb.1000087

the screening visit. Key exclusion criteria included use of prescription or nonprescription drugs, vitamins, or dietary supplements within 7 days or 5 half-lives (whichever is longer) before the first dose of study medication, except for acetaminophen at doses of $\leq 1 \mathrm{~g} /$ day; any clinically significant disease or drug allergies; febrile illness within the 5 days before first administration of study medication; sensitivity to heparin or heparin-induced thrombocytopenia; a positive test result for a drug of abuse; regular consumption of alcohol exceeding 14 drinks per week within the 6 months before the screening visit; excessive tobacco or nicotine use (equivalent to 5 cigars per day); an electrocardiogram showing QTc >450 $\mathrm{msec}$ at the screening visit; phosphodiesterase type 5 inhibitor use within the 4 days before first administration of the medicine under study; and treatment with nitrates or nitric oxide donors, either regularly or intermittently.

Blood samples were drawn from subjects before dosing and at $0.083,0.25,0.5,0.75,1,1.25,1.5,1.75,2,2.5,3,3.5,4,5,6,8,10,12$, and 16 hours postdose in each treatment period. Samples were collected in $6 \mathrm{ml}$ Vacutainer ${ }^{\circledR}$ tubes (BD Diagnostics, Franklin Lakes, NJ) using heparin as anticoagulant, then centrifuged at $4500 \mathrm{rpm}$ for 5 minutes to separate the plasma. Plasma samples were transferred to two 2-mL polypropylene cryogenic tubes (labeled retention sample and analysis, respectively) and immediately stored at $-70^{\circ} \mathrm{C}$.

Plasma concentrations of sildenafil were determined at Investigación Farmacológia y Biofarmacéutica S.A. de C.V. (Mexico D.F., Mexico) using an in-house developed and validated high-performance liquid chromatography method with ultraviolet detection. The plasma samples were extracted using liquid-liquid extraction, propranolol was used as the internal standard, and separation was through a reverse-phase column. The analytical methodology was developed and validated according to the requirements of the Official Mexican Standard [3]. Validation of the method was shown by determination of stability of standard solutions and stability of analyte in biological fluid under conditions of processing and during the storage period, and by selectivity tests, accuracy tests, precision tests, calculation of the quantification limit, regression model, recovery, and validation of the quality-control samples in 3 levels of concentration $(30 \mathrm{ng} / \mathrm{mL}$ [low], $1250 \mathrm{ng} / \mathrm{mL}$ [medium], and $2000 \mathrm{ng} / \mathrm{mL}$ [high]). The dynamic range of the assay was $10 \mathrm{ng} / \mathrm{mL}$ to $2500 \mathrm{ng} / \mathrm{mL}$. During performance of the analytical runs, the percentage relative SD (\% CV) of the quality control samples was $\leq 2.76 \%$ and the percentage relative error ranged from $2.23 \%$ to $8.29 \%$, across the range of tested nominal concentrations.

Vital signs were assessed at 1, 2, 4, 6, 10, and 16 hours postdose. Safety was assessed through adverse event reports and changes in vital signs and clinical laboratory test results.

The design of this study complied with the provisions of the Official Mexican Standard [3]. The study was approved by the site's Ethics and Research Committee and conducted in accordance with the Declaration of Helsinki, Japan Revision, and with Good Clinical Practices. All volunteers provided written and verbal informed consent before study enrollment.

\section{Statistical analyses}

Noncompartmental pharmacokinetic analysis was performed using WinNonlin version 5.2 software (Pharsight Corporation, Mountain View, CA, USA), and the following pharmacokinetic parameters were calculated:

$\mathrm{C}_{\max }$ : Maximum plasma concentration obtained graphically from the plasma concentration versus time profile
$\mathrm{T}_{\max }$ : Time to reach $\mathrm{C}_{\max }$ following drug administration, obtained graphically from the plasma concentration versus time profile

$\mathrm{AUC}_{0-\mathrm{t}}:$ Area under the plasma concentration-time curve from time 0 (administration) to time $t$ (last sampling time) calculated through the trapezoidal method

$\mathrm{AUC}_{0 \text {-inf: }}:$ Area under the plasma concentration-time curve from time 0 (administration) extrapolated to infinity

\section{$\mathrm{K}_{e}$ : Terminal elimination rate constant}

$\mathrm{t}_{1 / 2}$ : Elimination half-life, calculated as $\operatorname{Ln}(2) / \mathrm{K}_{\mathrm{e}}$

Natural log-transformed AUC parameters $\left(\mathrm{AUC}_{0-\mathrm{t}}\right.$ and $\left.\mathrm{AUC}_{0 \text {-inf }}\right)$ and $\mathrm{C}_{\max }$ of sildenafil were analyzed using a mixed-effect model with sequence, period, and comparator as fixed effects and subject within sequence as a random effect. Using geometric mean values, estimates of the adjusted mean differences (test - reference) and corresponding $90 \%$ CIs were obtained from the model. The adjusted mean differences and 90\% CIs for the differences were exponentiated to provide estimates of the ratio of adjusted means (test/reference) and $90 \%$ CIs for the ratios. Comparisons were made between conventional oral Viagra (reference) and the chewable tablet with or without water (test).

The pharmacokinetic parameters $\mathrm{AUC}_{0-\mathrm{t}}, \mathrm{AUC}_{0-\mathrm{inf}}, \mathrm{C}_{\max }, \mathrm{T}_{\max }$, and $t_{1 / 2}$ of sildenafil were summarized descriptively by treatment. Mean profiles of the concentration versus time data were plotted by treatment.

The average bioequivalence statistics assessed the difference between the comparators administered orally, by a logarithmic comparison of the pharmacokinetic parameters $\mathrm{C}_{\max }, \mathrm{AUC}_{0-\mathrm{t}}$, and $\mathrm{AUC}_{0 \text {-inf }}$ A statistical analysis was made on the bioequivalence of the medicines based on the construction of classic and Westlake CIs, which result favorably to bioequivalence if the limits calculated fall within the pre-established interval from $80 \%$ to $125 \%$ for data logarithmically converted [4]. These data were analyzed with a $90 \%$ confidence level, with statistical power of $>0.8$.

Limit tests were based on the rejection of the null hypothesis of nonbioequivalence, to conclude, with an alpha significance level (0.05) and confidence level to $90 \%$, that the comparators are bioequivalent. Limit tests applied were Schuirmann unilateral double $t$ test and the Anderson-Hauck test on the quotient between average of comparator

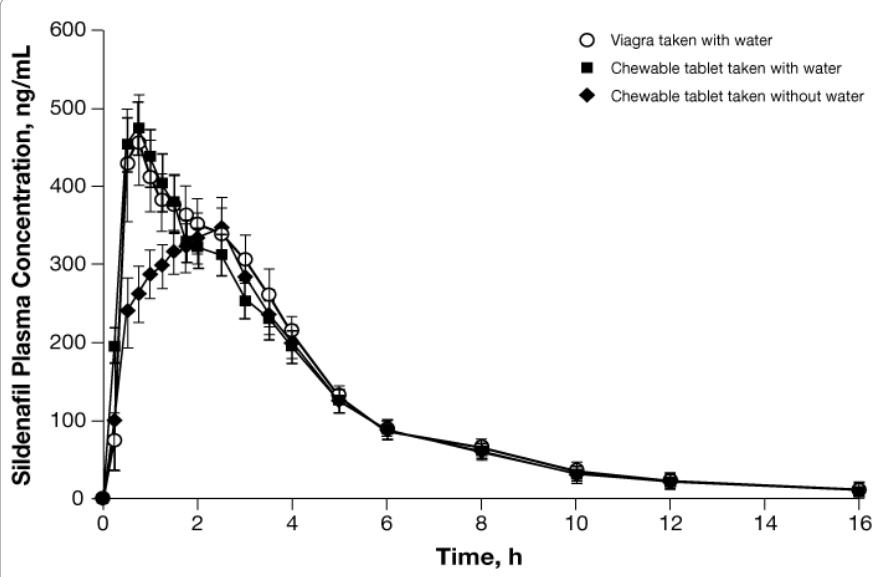

Figure 1: Mean (SE) plasma concentration over time for oral sildenafil $100 \mathrm{mg}$ administered as Viagra taken with water, the chewable tablet formulation taken with water, and the chewable tablet formulation taken without water. 
Citation: Valenzuela F, Davila G, Ibañez Y, Garcia L, Crownover P, et al. (2011) Relative Bioavailability of Chewable and Conventional Film-Coated Tablet Formulations of Sildenafil $100 \mathrm{mg}$ in Healthy Volunteers Under Fasting Conditions. J Bioequiv Availab 3: 207-210. doi:10.4172/ jbb.1000087

under study and comparator of reference, for pharmacokinetic parameters of $\mathrm{C}_{\max }, \mathrm{AUC}_{0-\mathrm{t}}$, and $\mathrm{AUC}_{0-\text { inf }}[5,6]$. The limit test results would conclude bioequivalence if there was a $<0.05$ probability that the quotient is $<80 \%$ and $>125 \%$.

\section{Results}

All 30 men who were enrolled completed the study. The mean \pm SD age for the study population was $24.4 \pm 3.7$ years (range, $20-35 \mathrm{y}$ ), mean weight was $69.9 \pm 7.6 \mathrm{~kg}$, mean height was $170.5 \pm 7.0 \mathrm{~cm}$, and mean body mass index was $24.1 \pm 2.2 \mathrm{~kg} / \mathrm{m}^{2}$.

\section{Pharmacokinetics and bioequivalence}

Mean sildenafil plasma concentration versus time profiles were nearly superimposable for Viagra and the chewable tablet taken with water; the chewable tablet taken without water resulted in a somewhat slower absorption rate, as indicated by lower $\mathrm{C}_{\max }$ compared with the chewable tablets or Viagra taken with water (Figure 1). The sildenafil $t_{1 / 2}$ averaged approximately 2.9 to 3.5 hours and did not appear to be treatment dependent, particularly when the standard deviation is taken into consideration (Table 1). Median $\mathrm{T}_{\max }$ was lowest for the chewable tablet taken with water $(0.75 \mathrm{~h})$ compared with Viagra $(1.0 \mathrm{~h})$ or the chewable tablet taken without water $(1.75 \mathrm{~h})$ (Table 1$)$.

The classic and Westlake CIs (asymmetric and symmetric intervals around $100 \%$, respectively) for logarithmically converted $\mathrm{AUC}_{0-\mathrm{t}}$ and $\mathrm{AUC}_{0 \text {-inf }}$ ratios were assessed as measures of the extent of systemic exposure. The intervals were contained within $80 \%$ to $125 \%$ for the chewable tablet taken with or without water, each compared with Viagra. Consistent with these statistical tests, the Schuirmann and Anderson-Hauck tests showed a high probability that AUC values fall within $80 \%$ to $125 \%(P<0.05)$, for which no statistically significant differences were found among the 3 comparators (Table 2).

For $\mathrm{C}_{\max }$ ratios of chewable tablet taken with water compared with Viagra, the lower limit of the classic CI was $<80 \%$ and the upper limit

\begin{tabular}{|c|c|c|c|}
\hline & $\begin{array}{l}\text { Viagra Conventional Film-Coated Tablet } \\
(n=30)\end{array}$ & $\begin{array}{l}\text { Chewable Tablet With Water } \\
(n=30)\end{array}$ & $\begin{array}{l}\text { Chewable Tablet Without Water } \\
(n=30)\end{array}$ \\
\hline $\begin{array}{l}\mathrm{T}_{\text {max }}, \mathrm{h} \\
\text { Mean (SD) } \\
\text { Median } \\
\mathrm{CV}, \% \\
\end{array}$ & $\begin{array}{l}1.42(0.95) \\
1.00 \\
66.7\end{array}$ & $\begin{array}{l}1.03(0.68) \\
0.75 \\
66.7\end{array}$ & $\begin{array}{l}1.62(0.80) \\
1.75 \\
49.2\end{array}$ \\
\hline $\begin{array}{l}\mathrm{C}_{\max }, \mathrm{ng} / \mathrm{mL} \\
\text { Mean }(\mathrm{SD}) \\
\text { Median } \\
\mathrm{CV}, \%\end{array}$ & $\begin{array}{l}657.64(332.58) \\
640.85 \\
50.6\end{array}$ & $\begin{array}{l}556.75(196.79) \\
506.92 \\
35.4\end{array}$ & $\begin{array}{l}517.46(244.20) \\
448.80 \\
47.2\end{array}$ \\
\hline $\begin{array}{l}\mathrm{AUC}_{0-\mathrm{t}}, \mathrm{h} \cdot \mathrm{ng} / \mathrm{mL} \\
\text { Mean }(\mathrm{SD}) \\
\text { Median } \\
\mathrm{CV}, \%\end{array}$ & $\begin{array}{l}1884.97(923.22) \\
1668.87 \\
49.0\end{array}$ & $\begin{array}{l}1803.45(859.73) \\
1571.24 \\
47.7\end{array}$ & $\begin{array}{l}1680.04(790.69) \\
1423.47 \\
47.1\end{array}$ \\
\hline $\begin{array}{l}\mathrm{AUC}_{0-\text {-inf }}, \mathrm{h} \cdot \mathrm{ng} / \mathrm{mL} \\
\text { Mean }(\mathrm{SD}) \\
\text { Median } \\
\mathrm{CV}, \%\end{array}$ & $\begin{array}{l}1983.03(1006.63) \\
1744.81 \\
50.8\end{array}$ & $\begin{array}{l}1907.12(978.50) \\
1630.51 \\
51.3\end{array}$ & $\begin{array}{l}1797.13(881.35) \\
1502.24 \\
49.0\end{array}$ \\
\hline $\begin{array}{l}\mathrm{K}_{\mathrm{e}}, \text { per } \mathrm{h} \\
\text { Mean }(\mathrm{SD}) \\
\text { Median } \\
\mathrm{CV}, \%\end{array}$ & $\begin{array}{l}0.259(0.094) \\
0.252 \\
36.5\end{array}$ & $\begin{array}{l}0.269(0.079) \\
0.282 \\
29.2\end{array}$ & $\begin{array}{l}0.244(0.094) \\
0.252 \\
38.3\end{array}$ \\
\hline $\begin{array}{l}\mathrm{t}_{1 / 2}, \mathrm{~h} \\
\text { Mean (SD) } \\
\text { Median } \\
\mathrm{CV}, \%\end{array}$ & $\begin{array}{l}3.06(1.23) \\
2.76 \\
40.1\end{array}$ & $\begin{array}{l}2.94(1.43) \\
2.46 \\
48.7\end{array}$ & $\begin{array}{l}3.45(1.88) \\
2.76 \\
54.6\end{array}$ \\
\hline
\end{tabular}

$\mathrm{AUC}_{0-\mathrm{inf}}=$ area under the plasma concentration vs time curve from time 0 extrapolated to infinity; $\mathrm{AUC}_{0-\mathrm{t}}=$ area under the plasma concentration vs time curve from time 0 to time $t ; \mathrm{C}_{\max }=$ maximum plasma concentration; $\mathrm{CV}=$ coefficient of variation; $\mathrm{K}_{\mathrm{e}}=$ elimination rate constant; $\mathrm{t}_{\mathrm{y} / \mathrm{2}}=$ elimination half life; $\mathrm{T}_{\text {max }}=$ time to reach $\mathrm{C}_{\max }$

Table 1: Pharmacokinetic Variables for Sildenafil $100 \mathrm{mg}$.

\begin{tabular}{|c|c|c|c|c|c|c|c|c|c|c|c|}
\hline \multirow{2}{*}{$\begin{array}{l}\text { Pharmacokinetic } \\
\text { Parameter }\end{array}$} & \multirow{2}{*}{$\begin{array}{l}\text { Reference } \\
\text { Mean }^{\mathrm{b}}\end{array}$} & \multirow[t]{2}{*}{ Test Mean ${ }^{\mathrm{b}}$} & \multirow{2}{*}{$\begin{array}{l}\text { Mean } \\
\text { Ratio (\%) }\end{array}$} & \multicolumn{2}{|c|}{ Classic Cl (\%) } & \multicolumn{2}{|c|}{ Westlake $\mathrm{Cl}(\%)$} & \multicolumn{2}{|c|}{$\begin{array}{l}\text { Schuirmann Unilateral } \\
\text { Double } t(\%)\end{array}$} & \multirow{2}{*}{$\begin{array}{l}\text { Anderson- } \\
\text { Hauck Test }\end{array}$} & \multirow[t]{2}{*}{ Power } \\
\hline & & & & Lower & Upper & Lower & Upper & Lower & Upper & & \\
\hline \multicolumn{12}{|l|}{$\mathrm{C}_{\max }, \mathrm{ng} / \mathrm{mL}$} \\
\hline CT with water & 579.29 & 526.11 & 90.82 & 78.93 & 104.49 & 81.41 & 118.59 & 0.0680 & 0.0002 & 0.0678 & 0.8365 \\
\hline CT without water & 579.29 & 455.55 & 78.64 & 68.35 & 90.48 & 70.54 & 129.46 & 0.5808 & 0.0000 & 0.5808 & 0.8365 \\
\hline \multicolumn{12}{|l|}{$A \cup C_{0-t}, h \cdot n g / m L$} \\
\hline CT with water & 1714.43 & 1663.47 & 97.03 & 90.94 & 103.52 & 92.18 & 107.82 & 0.0000 & 0.0000 & 0.0000 & 0.9999 \\
\hline CT without water & 1714.43 & 1525.19 & 88.96 & 83.38 & 94.92 & 84.61 & 115.39 & 0.0041 & 0.0000 & 0.0041 & 0.9999 \\
\hline \multicolumn{12}{|l|}{$\mathrm{AUC}_{0-\text { inf }}, \mathrm{h} \cdot \mathrm{ng} / \mathrm{mL}$} \\
\hline CT with water & 1800.71 & 1752.02 & 97.30 & 91.50 & 103.46 & 92.67 & 107.33 & 0.0000 & 0.0000 & 0.0000 & 1.0000 \\
\hline CT without water & 1800.71 & 1631.88 & 90.62 & 85.23 & 96.36 & 86.41 & 113.59 & 0.0006 & 0.0000 & 0.0006 & 1.0000 \\
\hline \multicolumn{4}{|l|}{ Criterion } & $\geq 80$ & $\leq 125$ & $\geq 80$ & $\leq 125$ & $<0.05$ & $<0.05$ & $<0.05$ & $>0.8$ \\
\hline
\end{tabular}

CT=chewable sildenafil 100-mg tablet.

aiagra conventional film-coated tablet.

beast squares geometric mean. 
Citation: Valenzuela F, Davila G, Ibañez Y, Garcia L, Crownover P, et al. (2011) Relative Bioavailability of Chewable and Conventional Film-Coated Tablet Formulations of Sildenafil $100 \mathrm{mg}$ in Healthy Volunteers Under Fasting Conditions. J Bioequiv Availab 3: 207-210. doi:10.4172/ jbb.1000087

was contained within $125 \%$; the Westlake CI was contained within the bioequivalence limits of $80 \%$ to $125 \%$. The Schuirmann test results for the lower limit were consistent with the classic CI results, whereas the Anderson-Hauck test failed to meet the established criteria. For the chewable tablet taken without water, both the classic and Westlake CIs were not contained within $80 \%$ to $125 \%$; the $\mathrm{C}_{\max }$ of the chewable tablet taken without water was about $22 \%$ lower than that of Viagra (Table 2).

\section{Safety}

A total of 17 adverse events were reported by 12 subjects following Viagra administration, 15 adverse events were reported by 13 subjects following chewable tablet administration with water, and 18 adverse events were reported by 13 subjects following chewable tablet administration without water. The most common adverse events that were considered probably related to the medicine were somnolence and headache (Table 3). Only a few of the 30 subjects in this study reported bitter taste with the chewable formulation (1 subject following administration with water and 4 subjects following administration without water; Table 3), indicating that unpleasant taste was successfully masked.

No statistically or clinically significant changes were noted in clinical laboratory test results compared with baseline values. Statistically significant decreases in systolic and diastolic blood pressure were recorded 1 to 4 hours after taking Viagra or chewable sildenafil with water and 4 to 6 hours after taking chewable sildenafil without water. These changes were not considered clinically meaningful.

\section{Discussion}

Administration of sildenafil $100 \mathrm{mg}$ as conventional filmcoated Viagra or a chewable tablet with water resulted in a similar pharmacokinetics, with rapid absorption $\left(\mathrm{T}_{\max }\right.$ within $1 \mathrm{~h}$ ) and elimination ( $\mathrm{t}_{1 / 2}$ about 3-3.5 h). The peak and extent of systemic exposures for the 2 treatments were similar, with the $90 \%$ CIs of the test/reference ratios contained within $80 \%$ to $125 \%$, establishing the existence of a fairly similar pharmacokinetic profile when administered with water. Chewable tablet taken without water showed a longer $\mathrm{T}_{\max }$ (median prolonged by about $0.75 \mathrm{~h}$ ) and lower $\mathrm{C}_{\max }$ (mean reduced by about $22 \%$ ), albeit with no statistically significant difference in the AUC, which means that the rate of absorption was slower but the total dose absorbed was equivalent. Therefore, for best results, it is recommended that doses of sildenafil citrate chewable tablet be taken with water. This may be particularly relevant for patients taking the 50-mg dose of sildenafil as the chewable tablet. For patients taking the 100 -mg dose of the chewable tablet, the $\mathrm{C}_{\max }$ reduction of about $22 \%$ when taken without water may not be clinically relevant because of the demonstrated efficacy of the 50-mg dose of Viagra, the standard recommended dose [7-9].

\begin{tabular}{|l|l|l|l|}
\hline & $\begin{array}{l}\text { Viagra } \\
\text { Conventional } \\
\text { Film-Coated } \\
\text { Tablet }\end{array}$ & $\begin{array}{l}\text { Chewable } \\
\text { Tablet With } \\
\text { Water }\end{array}$ & $\begin{array}{l}\text { Chewable Tablet } \\
\text { Without Water }\end{array}$ \\
\hline Somnolence & 9 & 6 & 7 \\
\hline Headache & 7 & 6 & 7 \\
\hline Visual photosensitivity & 1 & 1 & 0 \\
\hline Bitter flavor & 0 & 1 & 4 \\
\hline Nausea & 0 & 1 & 0 \\
\hline
\end{tabular}

Table 3: Treatment-Related Adverse Events Associated With Sildenafil $100 \mathrm{mg}$ ( $n=30$ subjects).
Adverse events reported with chewable sildenafil were similar whether taken with or without water and comparable with those of Viagra. Oral sildenafil $100 \mathrm{mg}$, regardless of formulation, resulted in clinically insignificant decreases in systolic and diastolic blood pressure, an effect that is well documented with Viagra [10-12]. These changes were not considered clinically meaningful.

In conclusion, sildenafil citrate chewable tablet taken with water has a pharmacokinetic profile similar to the conventional film-coated tablet (Viagra) taken with water. When taken without water, the chewable tablet has somewhat lower $\mathrm{C}_{\max }$ (reduced by about $22 \%$ ), delayed $\mathrm{T}_{\max }(1.75 \mathrm{~h}$ vs. $1.0 \mathrm{~h}$ ), and equivalent AUC compared with Viagra taken with water. The taste-masking technology used in this formulation was successful in making the chewable sildenafil citrate formulation palatable. In this study in healthy volunteers, the sildenafil citrate 100-mg chewable tablet formulation was well tolerated, with reported adverse events that were consistent with the tolerability profile of Viagra.

\section{Acknowledgments}

The authors thank Mario Ulises Perez-Toriz of Hospital Ángeles Puebla, Puebla, Pue, Mexico, for his valuable assistance. This study was sponsored by Pfizer Inc. Editorial support was provided by Deborah M. Campoli-Richards, BSPharm, RPh, of Complete Healthcare Communications, Inc., and was funded by Pfizer Inc.

\section{References}

1. Nichols DJ, Muirhead GJ, Harness JA (2002) Pharmacokinetics of sildenafil citrate after single oral doses in healthy male subjects: absolute bioavailability, food effects and dose proportionality. Br J Clin Pharmacol 53: 5S-12S.

2. Boolell M, Allen MJ, Ballard SA, Gepi-Attee S, Muirhead GJ, et al. (1996) Sildenafil: an orally active type 5 cyclic GMP-specific phosphodiesterase inhibitor for the treatment of penile erectile dysfunction. Int J Impot Res 8: 4752.

3. Mexican Department of Health (1999) Official Mexican Standard NOM-177 SSA1-1998, which sets forth tests and procedures to prove that any medicine is interchangeable. Requirements to be observed by authorized third parties performing the tests: Official Gazette of the Federation; May 7, NOM-177SSA1-1998.

4. Westlake WJ (1976) Symmetrical confidence intervals for bioequivalence trials Biometrics 32: 741-744.

5. Hauck WW, Anderson S (1984) A new statistical procedure for testing equivalence in two-group comparative bioavailability trials. J Pharmacokinet Biopharm 12: 83-91.

6. Schuirmann DJ (1987) A comparison of the two one-sided tests procedure and the power approach for assessing the equivalence of average bioavailability. $J$ Pharmacokinet Biopharm 15: 657-680.

7. Viagra $^{\circledR}$ (sildenafil citrate), Reg. $\mathrm{N}^{\circ} 213 \mathrm{M} 98$ SSA IV LPD Authorization $\mathrm{MoH}$ CODE: 083300RR010163. Full Prescribing Information, Pfizer Inc, Mexico, 2007.

8. European Medicines Agency (2008) VIAGRA Summary of Product Characteristics.

9. Food and Drug Administration (2010) VIAGRA ${ }^{\circledR}$ (sildenafil citrate) tablets. Ful Prescribing Information (approved labeling [LAB-0220-7.0]). Silver Springs, $\mathrm{MD}$

10. Kloner RA (2004) Novel phosphodiesterase type 5 inhibitors: assessing hemodynamic effects and safety parameters. Clin Cardiol 27: I20-25.

11. Webb DJ, Freestone S, Allen MJ, Muirhead GJ (1999) Sildenafil citrate and blood-pressure-lowering drugs: results of drug interaction studies with an organic nitrate and a calcium antagonist. Am J Cardiol 83: 21C-28C

12. Zusman RM, Prisant LM, Brown MJ (2000) Effect of sildenafil citrate on blood pressure and heart rate in men with erectile dysfunction taking concomitant antihypertensive medication. Sildenafil Study Group. J Hypertens 18: 18651869 